\title{
Riesgos laborales en Medicina Veterinaria en América Latina y el Caribe. Revisión
}

\section{Occupational risks in Veterinary Medicine in Latin America and the Caribbean. A review}

\author{
Héctor D. Tarabla ${ }^{1}$
}

1 Cátedra de Epidemiología, Facultad de Ciencias Veterinarias, Universidad Nacional del Litoral, Kreder 2805, 3080 Esperanza, Santa Fe, Argentina htarabla@fcv.unl.edu.ar

Recibido: 30 de Junio de 2017. Corregido: 10 de Octubre de 2017.Aceptado: 20 de Octubre de 2017.

Resumen: Los Médicos Veterinarios están expuestos a peligros físicos, biológicos, químicos y radiaciones. Los objetivos de este trabajo consisten en revisar sus accidentes laborales (AL) y enfermedades profesionales (EP), factores y percepciones de riesgo, uso y disposición de elementos de protección personal (EPP) en América Latina y el Caribe. La frecuencia de profesionales que sufren accidentes, in labore, es muy alta; con la consecuente pérdida de días laborales. Los AL varían según la especie animal. Los más frecuentes son: mordeduras, rasguños, atropellamientos y aprisionamientos por animales, así como heridas por elementos punzocortantes. En clínica de grandes animales, la zoonosis más diagnosticada es la brucelosis; en la práctica con pequeñas especies, dermatofitosis y sarna. Entre las EP de origen ergonómico, se destacan las afecciones músculo esqueléticas (columna y articulaciones). La atención clínica no se percibe como de alto riesgo; aunque la mayor parte de los AL ocurre en dichas instancias. La frecuencia de uso de EPP varía en las distintas actividades profesionales y poblaciones relevadas. Los guantes son los más utilizados; mientras que la falta de uso de protectores oculares o faciales es muy evidente. No hay asociaciones entre percepción del riesgo y uso de EPP. En general, ambas son más frecuentes entre las mujeres y los jóvenes. La disposición final de insumos descartables, muchas veces, es inapropiada. La percepción de riesgos y la adopción de buenas prácticas, in itinere, es mayor en rutas principales que en caminos rurales; sin embargo, los AL son más frecuentes en estos últimos. Los AL y las EP no deben ser asumidos como algo natural, de ocurrencia corriente, que no requiere acción alguna. Es necesario cambiar conductas y actitudes en el ejercicio de la profesión, mejorar las condiciones de trabajo, concientizar las nuevas generaciones de profesionales y cumplir con el deber social de ser agentes de Salud Pública.

Palabras clave: salud ocupacional, práctica veterinaria, factores de riesgo, percepción del riesgo, elementos de protección personal.

Abstract: Veterinarians are exposed to physical, biological, chemical and radiation hazards. The objective of this
study was to review work accidents (WA) and diseases (WD), risk factors and perceptions, use and disposal of
personal protective equipment (PPE) in Veterinary Medicine in Latin America and the Caribbean. Frequency
of work accidents for veterinarians is very high, with the resulting loss of working days. WAs vary according
to animal species. The most frequent WAs were bites, scratches, running over/imprisonment by animals and
wounds caused by sharp objects. The most frequently diagnosed zoonosis in large animal clinics was brucellosis,
while dermatophytosis and scabies in small animal practices. Injuries of an ergonomic nature include
musculoskeletal injuries (spine and joints). Clinical practice was not perceived as a high-risk activity, although
most WAs occurred in those instances. Frequency of use of PPE varied depending on the different professional
activities and populations surveyed. Gloves were the most used PPE, while the lack of use of protective goggles
or face masks was very evident. There were no associations between risk perception and use of PPE. In general,
both were higher among women and young veterinarians. The final destination of disposable material was often
inappropriate. Risk perception and adoption of good practices in itinere was greater along main roads than 
along rural roads, but WAs were more frequent in the latter. WAs and WDs should not be assumed to be a natural occurrence not requiring any action. Behaviors and attitudes in the veterinary practice need to change; working conditions must be improved; awareness should be raised with new generations of professionals; and veterinarians should comply with their social duty as public health agents.

Keywords: occupational health, Veterinary practice, risk factors, risk perception, personal protective equipment.

\section{Introducción.}

El ejercicio dela Medicina Veterinaria estáasociado a accidentes laborales(AL) y enfermedades profesionales (EP). Algunas características y actitudes de los profesionales, unidas a la especial naturaleza de los pacientes, las instalaciones inapropiadas para la práctica clínica, la necesidad de trasladarse en vehículos automotores y la exposición a material biológico, radiaciones y sustancias peligrosas, contribuyen para que la profesión tenga un alto riesgo laboral. Sin embargo, las publicaciones basadas en investigaciones originales, realizadas en América Latina y el Caribe, son escasas en comparación con las generadas en otros lugares como: Australia, Canadá, Estados Unidos y los países europeos. Hasta el 2000, sólo se habían registrado dos publicaciones originadas en Sud y Centroamérica, México y el Caribe (Riemann et al. 1974; Álvarez et al. 1990), aunque, recientemente, parece existir un interés creciente sobre el tema.

Esta revisión tiene el propósito de discutir la importancia de los AL, las EP, los factores y las percepciones de riesgo, el uso y la disposición de elementos de protección personal (EPP) y las recomendaciones básicas de buenas prácticas profesionales en estudiantes y Veterinarios de la región. En la búsqueda bibliográfica, se tomaron en cuenta trabajos completos de revistas indexadas y comunicaciones cortas en Congresos y otras reuniones científicas.

\section{Accidentes in labore.}

Los AL, en estudiantes de Veterinaria, se producen mayoritariamente durante revisiones clínicas de pacientes, el trabajo con bovinos y la vacunación de pequeños animales. Estudios efectuados en Argentina (Figura 1), Brasil y México muestran que la frecuencia de AL fue variable (53-86\%).. La mayoría de casos corresponden a pinchazos con agujas, 32-43\%; accidentes con animales: rasguños, 27-49\%, mordeduras, 18-32\% y aprisionamientos o atropellamientos, 14-18\%, patadas, 32\%; exposición solar excesiva, 27-34\% y cortes con objetos de vidrio, bisturí o cuchillo, 11-34\% (Torres da Silva et al. 2001, Olvera Yabur et al. 2015, 2016; Arce et al. 2016, Tarabla et al. 2016).

Los encuestados que sufrieron accidentes tenían más años como estudiante de veterinaria $(\mathrm{P}=0,034)$; lo cual indica una relación con el tiempo de exposición. Los varones sufrieron atropellamientos $(\mathrm{P}=0,005)$ y patadas $(\mathrm{P}=0,002)$ por animales, con mayor frecuencia que las mujeres; mientras que, estas últimas, padecieron más rasguños, pinchazos, contusiones contracturas $(\mathrm{P}<0,05)$. Las lesiones más frecuentes son heridas punzocortantes, $30 \%$ y contusiones, $22 \%$, localizadas, mayoritariamente, en extremidades superiores (Olvera Yabur et al. 2016, Tarabla et al. 2016).

En veterinarios de práctica mixta, los traumatismos y las heridas punzocortantes aparecen como las consecuencias más frecuentes de los AL. Tres de cada cuatro profesionales habían sufrido AL durante 


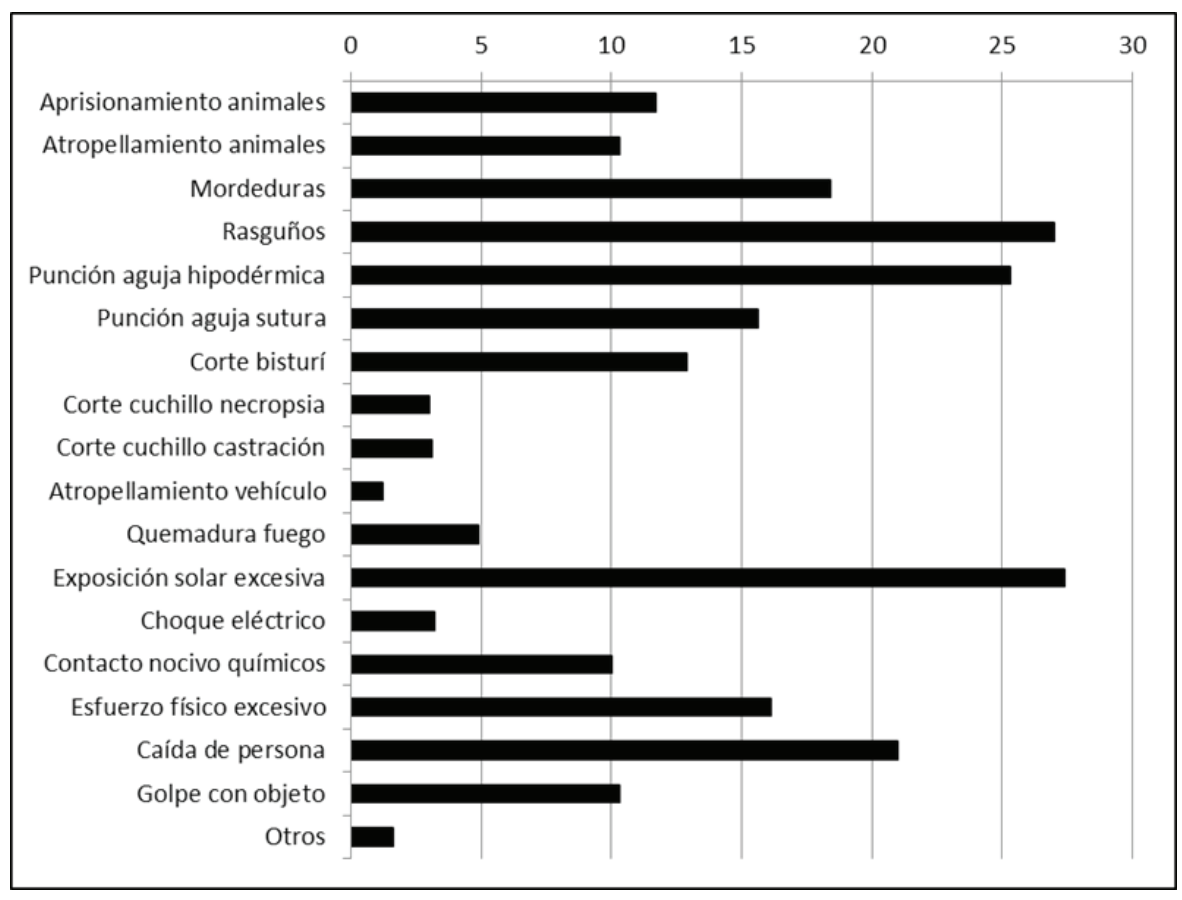

Figura 1. Frecuencia (\%) de estudiantes que sufrieron accidentes ocupacionales y características de los accidentes $(n=778)$ (Tarabla et al. 2016).

su último año de trabajo y el 19\% sufrió algún accidente grave a lo largo de su trayectoria profesional (Tarabla 2009, Imoberdorf et al. 2017 ). Esta frecuencia no debe ser minimizada, porque la calificación de los accidentes de acuerdo con la percepción individual es un parámetro muy relativo. Los Veterinarios tienen una tendencia a minimizar los AL, tratarse a sí mismos y a continuar trabajando aún lesionados (Tarabla 2009, Lecaros et al. 2010). El 51\% de Veterinarios de bovinos y equinos había trabajado en inferioridad de condiciones físicas y el 74\% se auto-medicó luego de un AL (Navarrete \& Tarabla 2916). Los Veterinarios son reticentes a buscar consejos de médicos para humanos. El autotratamiento, luego de un trauma, es frecuente. Esto incluye no sólo la automedicación, sino, circunstancialmente, la sutura de heridas y la reducción de fracturas y luxaciones.

En Veterinarios de grandes especies, en Argentina, casi la totalidad, 97-99\%, (Signorini et al. 2014; Navarrete \& Tarabla 2016) han tenido al menos un AL a lo largo de su carrera profesional. Las lesiones más frecuentes son: contusiones, contracturas, escoriaciones y heridas, principalmente en miembros superiores, 53\% e inferiores, 30\% (Navarrete \& Tarabla 2016). Las instalaciones inadecuadas fueron también un factor de riesgo importante, no sólo para los profesionales de grandes animales (Figura 2), sino también para los estudiantes de Veterinaria (Arce et al. 2016, Benzoni et al. 2017 ).

El 60\% de los clínicos de grandes especies, accidentados, requirió atención médica. El 52\% tuvo, al menos, un día de ausencia laboral debido a accidentes de trabajo (37,9 $\pm 51,7$ días). Las principales lesiones articulares son: esguince, 19\%; luxación, 6\%; distensión de ligamentos, 6\% y hernia de disco, $1 \%$. Las lesiones musculares incluyen contracturas y desgarros, mientras que las óseas consisten en 


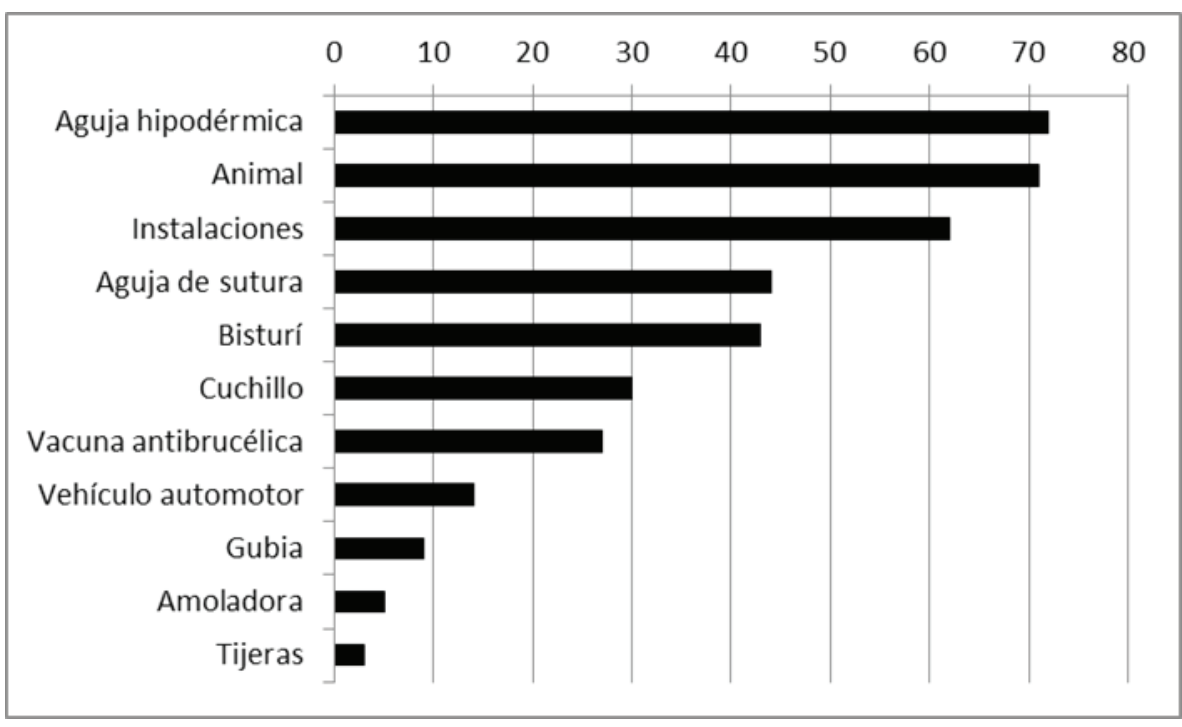

Figura 2. Frecuencia (\%) de accidentes laborales en Veterinarios de grandes animales $(n=562)$ de acuerdo con el elemento involucrado (Signorini et al. 2014).

fracturas y fisuras (Signorini et al. 2014). En profesionales dedicados a la producción porcina, el $84 \%$ sufrió AL; cuatro de cada 10 accidentados requirió atención médica y el 44,7\% tuvo ausencias laborales (18,4 $\pm 14,2$ días) (Ugnia et al. 2017). Por su parte, sobre un total de 85 jóvenes veterinarios de Boyacá, Colombia (33,8 $\pm 8,2$ años), el 92\% tuvo, por los menos, un AL que involucró la presencia de animales, agujas, bisturí y/o un medio de movilización al lugar de trabajo (López Cepeda et al. 2014).

Información proveniente de Argentina y Perú, (Breña et al. 2014; Gómez de la Torre \& Tarabla 2016) dio cuenta que las lesiones en profesionales de pequeñas especies son consecuencia de: pinchazos, 78\%; mordeduras, 78\%; rasguños, 74\%; cortes, 43,5\% y reacciones alérgicas, $28 \%$. El 13\% requirió atención médica y tuvo, al menos, un día de ausencia laboral. La mayoría de los animales llegan al consultorio sin bozal y, aunque las mordeduras producen heridas menores, las complicaciones por infecciones polimicrobianas son frecuentes si no se trata la herida de manera rápida y eficaz. Estos AL son también frecuentes en profesionales que trabajaban con porcinos (Ugnia et al. 2017) o con fauna silvestre (Lecaros et al. 2010). Entre estos últimos, el 85.6\% sufrió ataques de animales; las mordidas causadas por primates y carnívoros son las más frecuentes. Las manos, $68.9 \%$ y brazos, 20.2\% son las regiones anatómicas más afectadas y las cicatrices la secuela más común, 49.9\% (Lecaros et al. 2010, Villar \& Ortiz 2016).

Las heridas punzocortantes son las lesiones más frecuentes en la práctica veterinaria. Están relacionadas con la impericia, los descuidos, la tendencia a volver a cubrir la aguja hipodérmica usada con su cobertor original, la carencia de recipientes para disposición de agujas y el movimiento de los pacientes durante los procedimientos médicos. Si bien la mayoría de las heridas punzantes son de carácter leve y la probabilidad de transmisión de zoonosis es baja, el mayor peligro es la inyección accidental de compuestos biológicos, especialmente vacunas y drogas parenterales como: antibióticos, quimioterapéuticos, eutanásicos, tranquilizantes y anestésicos. 
El 44\% de los Veterinarios de bovinos y equinos estuvo expuesto por contacto (piel, mucosas o autoinoculación) con compuestos químicos o biológicos potencialmente peligrosos (Navarrete \& Tarabla 2016). Muchas sustancias utilizadas en la práctica veterinaria pueden causar diversos daños, dadas sus características: mutagénicas, teratogénicas, carcinogénicas, tóxicas, irritantes, alergénicas, infecciosas, inflamables o explosivas. Ocho de cada diez clínicos de pequeñas especies tuvo contacto directo con sustancias potencialmente nocivas, $70 \%$ en piel (corrosivos, hormonas o antiparasitarios percutáneos) y $57 \%$ en mucosas: formalina o yodóforos; mientras que, un tercio había sufrido quemaduras con cáusticos (Navarrete \& Tarabla 2016). En Perú, el 31,2\% de los profesionales de zoológicos y zoocriaderos manifestó malestares por químicos utilizados en el trabajo. El 75,6\% de los eventos fueron ocasionados por desinfectantes y esterilizantes, el 20,0\% por formol y los restantes por otros químicos como insecticidas y líquido de revelado (Lecaros et al. 2010).

\section{Accidentes in itinere.}

Los accidentes viales, durante el traslado por razones laborales, son eventos frecuentes. En Argentina, prácticamente cuatro de cada 10 veterinarios de práctica mixta padecieron accidentes de tránsito durante el ejercicio de sus tareas profesionales (Tarabla 2009). La mayoría de estos accidentes se produce en caminos rurales (Fig.3); su frecuencia varía en las diferentes áreas geográficas $(\mathrm{P}<0,01)$ (Molineri et al. 2016). Es interesante notar que la frecuencia de estos accidentes, en veterinarios de pequeñas especies, también es importante, 17\%.(Gómez de la Torre \& Tarabla, 2016).

Los $\mathrm{AL}$, in itinere, causan lesiones que muchas veces requieren de recuperaciones más prolongadas que los AL in labore. En profesionales, dedicados a la producción porcina, el 25\% sufrió accidentes de tránsito in itinere. El $72 \%$ requirió atención médica y $20 \%$ internación hospitalaria y son más frecuentes en hombres que en mujeres $(\mathrm{P}=0,021)$ (Ugnia et al. 2017). En Veterinarios de grandes animales, los factores más

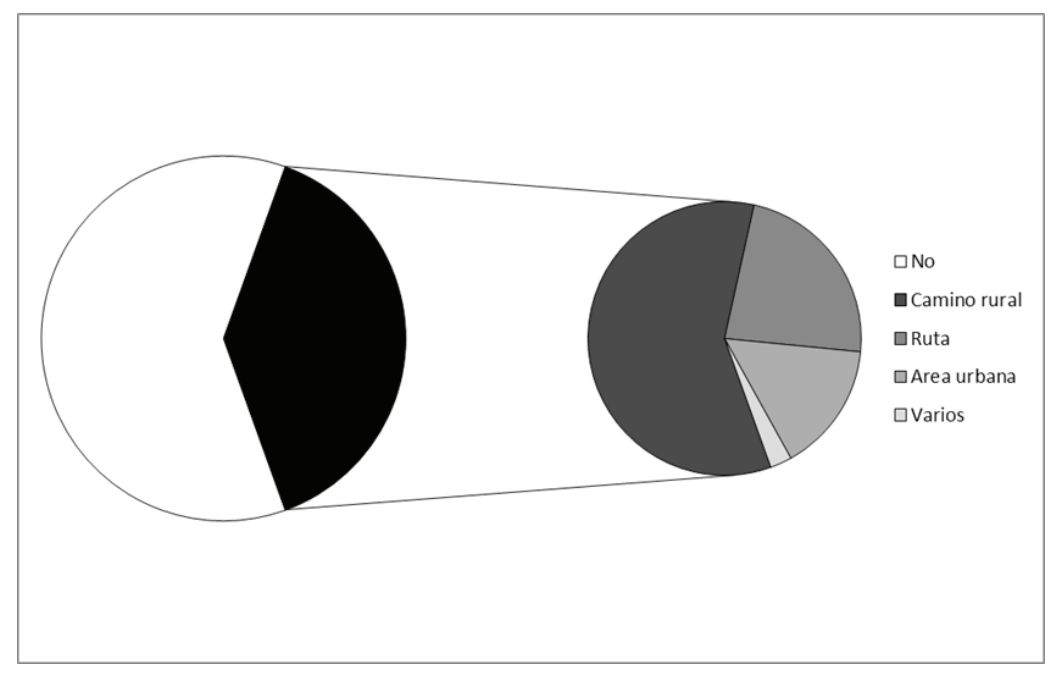

Figura 3. Accidentes viales, in itinere, en Veterinarios de práctica mixta $(n=95)$ (Tarabla 2009). 
frecuentemente identificados, en asociación con estos accidentes, son el estado psicofísico: cansancio, estrés, sueño, el comportamiento de otros conductores, el estado e infraestructura de los caminos, las condiciones climáticas, la propia conducción, el cumplimiento de horarios y los animales sueltos (Huertas et al. 2017 $)$.

\section{Enfermedades profesionales.}

\section{Zoonosis.}

Entre las EP asociadas a la Medicina Veterinaria, las zoonosis están entre las más relevantes, dado el contacto directo de los trabajadores con: animales, sus secreciones, excreciones, productos, subproductos, cadáveres y muestras de material biológico. El 14\%, de 780 estudiantes de Veterinaria de 13 Universidades argentinas, había sufrido alguna zoonosis. Las más frecuentes fueron dermatofitosis, brucelosis y toxoplasmosis (Tarabla et al. 2016). Las picaduras de garrapatas son eventos relevantes en algunas regiones de México (Olvera Yabur et al. 2015, 2016). La alta prevalencia de anticuerpos contra Toxoplasma gondii, 46\% y Coxiella burneti, 22\%, entre estudiantes y personal universitario, se demostró en Brasil hace más de 40 años (Riemann et al. 1974). Más recientemente, la seroprevalencia de toxoplasmosis fue del 30,3 y 26,4\% en estudiantes de Brasil y Argentina, respectivamente (Ribeiro de Araújo 2000, Trabattoni et al. 2008); del 0,8\% para mal de Chagas (Trabattoni et al. 2008). Por su parte, la prevalencia de anticuerpos antileptospiras fue importante en estudiantes de Brasil (Carneiro et al. 2004), Colombia (Góngora et al. 2008, Cristancho et al. 2012, Suescún Carrero et al. 2017), Perú (Dammert et al. 2009) y Trinidad y Tobago (James et al. 2013), mientras que la de brucelosis varió entre el dos y el 18\% de los estudiantes muestreados en dos regiones de Argentina (Trabatoni et al. 2004) y Colombia (Méndez et al. 2013), respectivamente.

La tasa de incidencia acumulada de brucelosis, en Veterinarios rurales, puede llegar hasta el 29\%. Esta tasa está asociada a la antigüedad laboral y a la región geográfica de ejercicio profesional. Los veterinarios que trabajan en zonas de cría de ganado de carne tienen dos veces menos riesgo de enfermar que quienes lo hacen en cuencas lecheras, $(\mathrm{P}=0,0099)$. Obviamente, a mayor tiempo de exposición, mayor riesgo de enfermedad. El riesgo de brucelosis fue 5 veces mayor entre quienes se habían graduado hacía 11-20 años y 8 veces mayor entre los graduados hacía más de 20 años que los graduados en los últimos 10 años (P> 0,0001) (Molineri et al. 2013). En general, los profesionales sufrieron las enfermedades zoonóticas durante los primeros años de actividad profesional (Molineri et al. 2013, Huertas et al. 2017 , Imoberdorf et al. 2017 ). La tasa de densidad de incidencia de brucelosis en clínicos de grandes animales fue del $20 \%$ y resultó más alta en los primeros años posgraduación. En regiones bajo programas de control y erradicación de brucelosis bovina esta tasa disminuye con el correr de los años, al lado del descenso de la tasa de bovinos enfermos (Molineri et al. 2013). El 20\% tuvo accidentes vinculados con vacunas antibrucélicas (roturas de frascos o jeringas, aerosol en los ojos o autoinoculación con agujas hipodérmicas). Sin embargo, sólo el 3\% cataloga el hecho como grave (Tarabla 2009). La alta frecuencia de brucelosis, sin embargo, no debe desviar la atención de la importancia de otras zoonosis detectadas entre los profesionales de la región, las cuales incluyen: leptospirosis, tuberculosis, carbunco, dermatofitosis, mal de Chagas, psitacosis, salmonelosis, coriomeningitis, estafilococosis, paludismo, 
toxoplasmosis, criptosporidosis, triquinosis, hidatidosis, sarna, tiña e infestaciones con pulgas y garrapatas (Alvarez et al. 2007, Góngora et al. 2008, Quitián et al. 2009, Tarabla 2009, Neira et al. 2010, Molineri et al. 2013,Huertas et al. 2017 $)$.

Así como la brucelosis en Veterinarios se relaciona con la práctica en grandes animales, específicamente en bovinos, la práctica en pequeñas especies está asociada a afecciones de la piel (Molineri et al. 2013, Gómez de la Torre \& Tarabla 2016, Huertas et al. 2017 , Imoberdorf et al. 2017b) (Figura 4).

En clínicos de pequeños animales, el $48 \%$ manifesta haber padecido alguna zoonosis: tiña $26 \%$, brucelosis 13\%, sarna 13\%, psitacosis $9 \%$, enfermedad por arañazo de gato, (Bartonella henselae)

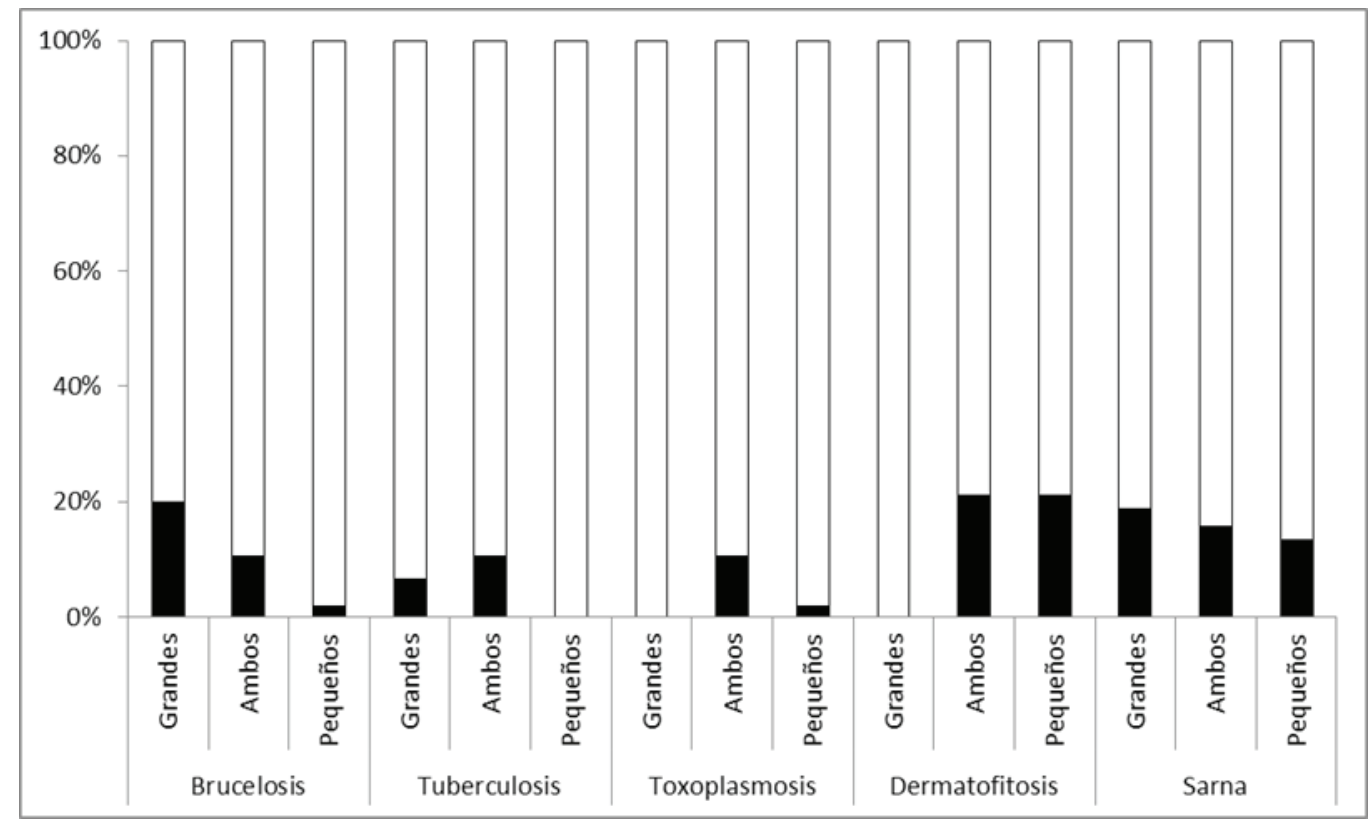

Figura 4. Zoonosis diagnosticadas en clínicos de grandes y pequeños animales $(n=95)$ (Imoberdorf et al. 2017b).

4\%, lo cual confirma que las parasitosis externas son eventos frecuentes entre estos profesionales. Quienes comunicaron padecer brucelosis habían trabajado, previamente, con bovinos (Gómez de la Torre \& Tarabla 2016). Por su parte, entre los veterinarios de zoológicos, se cuenta con dos aportes de investigadores peruanos y brasileños, quienes comunican una prevalencia de zoonosis del 14,4\%; (Lecaros et al. 2010) una seroprevalencia de psitacosis del 5\% (Raso et al. 2009), respectivamente.

Es de destacar que, en el caso de brucelosis, muchos diagnósticos no presentan signos clínicos, lo cual acentúa la importancia de los exámenes periódicos; práctica que no siempre forma parte de la rutina preventiva entre los veterinarios en Latinoamérica. Por otra parte, en enfermedades como la rabia, los individuos en constante actividad en Hospitales Veterinarios de áreas endémicas, carecen muchas veces de un seguimiento epidemiológico y serológico que corrobore su protección contra la enfermedad luego de ser vacunados preexposición (Nocifi et al. 2003). 
Otro aspecto de importancia es la responsabilidad social del Veterinario, dado que la población tiene un conocimiento parcial de las zoonosis (Tarabla \& Fermández 2009; Molineri et al. 2014; Koziol et al. 2016, Henzenn et al. 2017). Trabajos efectuados en Argentina, Colombia y Cuba muestran que esto también incluye a recién ingresados a la carrera de Veterinaria (Molineri et al. 2014 a), a estudiantes (Cristancho et al. 2012, Benzoni 2017a) y a profesionales no dedicados a la salud pública (Suarez et al. 2005, Vallejo et al. 2016). Los veterinarios tienen el deber social ineludible de constituirse en agentes de salud pública, capacitadores de estudiantes, las familias, los clientes y el resto de la sociedad, a fin de disminuir el impacto de las zoonosis transmitidas por la fauna silvestre, las mascotas y los animales productores de alimentos.

\section{Otras enfermedades.}

Más allá de las zoonosis, hay otras EP que afectan a quienes practican la Medicina Veterinaria. El 81\% de veterinarios de grandes animales tuvo dolencias músculo esqueléticas atribuibles al ejercicio profesional (Signorini et al., 2014). En profesionales de práctica mixta esta cifra es del 53\%: columna 32\%, articulaciones $20 \%$, otras $1 \%)$, Entre estas afecciones se destacan los problemas lumbares (25\%) y de hombros (10\%) (Tarabla, 2009).

En un censo a Veterinarios de Uruguay, el 67\% declara haber adquirido, al menos, una afección durante el ejercicio de la profesión, siendo la lumbalgia la más frecuente, 36\% (Gil et al. 2010). Por su parte, el $83 \%$ de profesionales, dedicados a las pequeñas especies, manifiesta tener dolencias físicas atribuibles a malas posturas in labore: espalda, 65\%; cuello, 57\%; extremidades, 13\%. El 26\% requirió atención médica; el 13\% tuvo, al menos, un día de ausencia laboral por problemas ergonómicos. El 48\% contaba con camilla regulable en altura, aunque su mera posesión no asegure que el profesional la regule según su necesidad (Gómez de la Torre \& Tarabla 2016). En veterinarios de zoológico, se observan cifras igualmente elevadas de lesiones, $72,8 \%$, por mala postura. El $44.5 \%$ comunica problemas músculo esqueléticos en espalda, cuello y/o extremidades. (Lecaros et al. 2010).

\section{Percepción de riesgos ocupacionales.}

El 52\% de los estudiantes tuvo conocimientos adecuados sobre bioseguridad (Torres da Silva et al. 2001), mientras que los hábitos y comportamientos personales, al respecto, pueden distar mucho de lo ideal (Langoni et al. 2009). Más aún, aunque los conocimientos teóricos sean apropiados, esto no asegura su estricta aplicación en las actividades prácticas inherentes a la carrera (Benzoni et al. 2017a). La atención clínica se percibe, mayoritariamente, como de riesgo medio o bajo: bovinos, 75,8\%; equinos, 63\%; porcinos, 90\%; ovinos, 94\%; pequeñas especies, 91\%; aves de corral, 94\% (Olvera Yabur et al. 2016). En general, las percepciones son mayores en las prácticas con bovinos y fauna silvestre que con otras especies $(\mathrm{P}<0.002)$ (Olvera Yabur et al. 2016). Los estudiantes avanzados en la carrera y las mujeres muestran, en general, mayor percepción de los riesgos ocupacionales que los alumnos de los primeros cursos, $(\mathrm{P}<0,01)$ (Tarabla et al. 2016).

En los profesionales de grandes especies, la atención clínica también se percibe como de riesgo bajo o medio (Tarabla et al. 2017); contrastando con el hecho de que la mayor parte de los AL haya sido en 
estas instancias (Tarabla 2009; Signorini et al. 2014). Algunas percepciones no reflejan el peligro real de determinadas actividades y actitudes. La percepción del riesgo, en tareas ciertamente riesgosas, como las necropsias a campo, son calificadas como de riesgo alto por la mitad de encuestados, así como el tacto rectal, actividad relacionada con la presentación de patologías crónicas en miembros superiores, la cual se considera como de riesgo medio o bajo por tres de cada cuatro profesionales (Figura 5) (Tarabla et al. 2017).

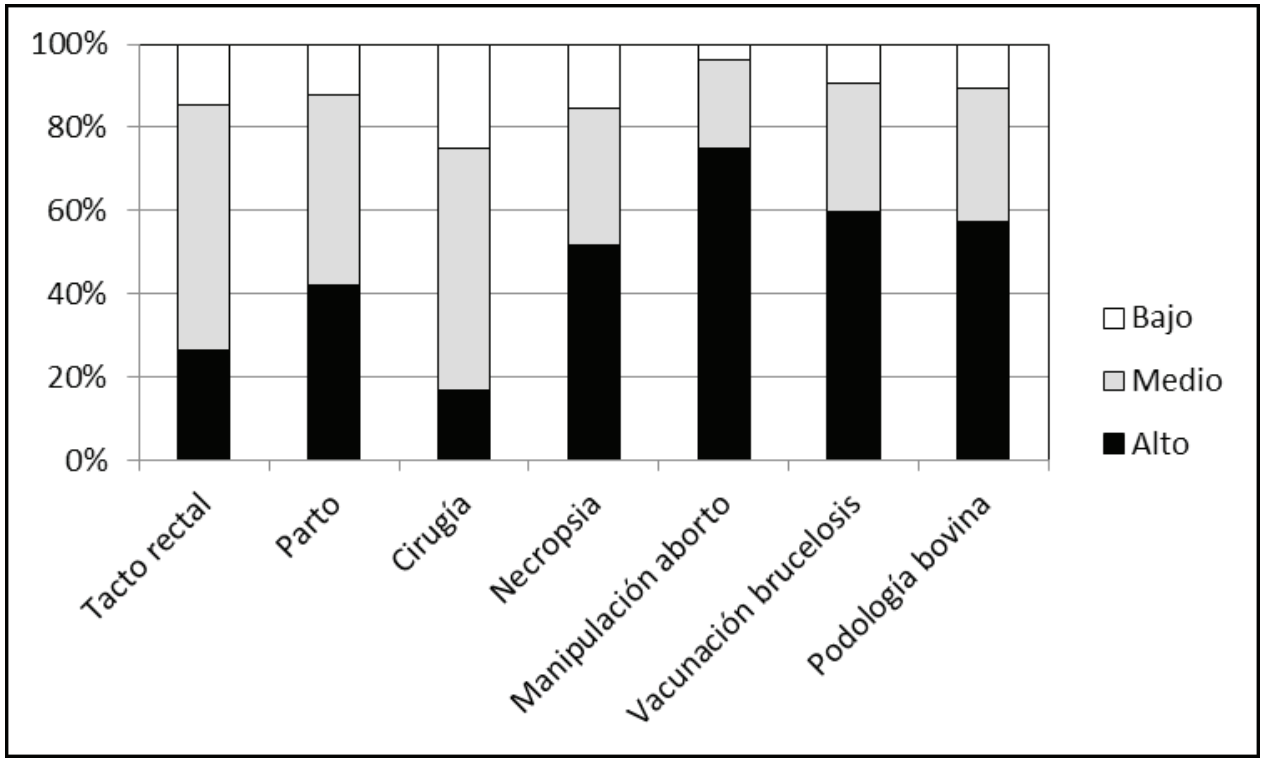

Figura 5. Percepciones de riesgos laborales (\%) de veterinarios rurales con accidentes laborales de acuerdo con el elemento involucrado $(n=562)$ (Tarabla et al. 2017).

Las percepciones de riesgo son mayores en las mujeres que en los hombres. y tienden a disminuir a medida que aumentan los años de experiencia laboral $(\mathrm{P}<0,01)$. La percepción del riesgo de accidentes en el tránsito in itinere está asociada con la región geográfica $(\mathrm{P}<0,01)$. El tránsito, en rutas principales, se considera más riesgoso que en caminos rurales (Tarabla et al. 2017), lo cual se contrapone con la mayor frecuencia real de accidentes en los últimos (Signorini et al. 2014, Tarabla 2009).

\section{Uso de elementos de protección personal.}

Los estudiantes utilizan los diferentes EEP de manera dispar (Benzoni et al. 2017a). Los guantes son los elementos más utilizados, aunque su frecuencia de uso varía entre las prácticas y las exigencias de los docentes en distintas Universidades (Olvera Yabur et al. 2015, 2016, Tarabla et al. 2016). En una investigación efectuada en Argentina, no hubo asociaciones entre el uso de EPP con las percepciones de riesgos y los años como estudiante de Veterinaria (Tarabla et al. 2016). 
La bioseguridad es un tema relativamente reciente entre los Veterinarios (Labarthe \& Pereira 2008). Hasta hace pocos años, en las carreras de grado. no existía una enseñanza metódica de seguridad e higiene laboral, aunque algunas Facultades tenían programas y comisiones institucionales específicas sobre estos temas (Álvarez et al. 2002). Esto ha cambiado con la actualización de las legislaciones vigentes, las exigencias de cada institución y los procesos de acreditación de las carreras por parte de organismos nacionales y multilaterales.

En profesionales de práctica mixta, en Argentina (Tarabla 2009) y Colombia (López Cepeda et al. 2014), la frecuencia de uso de guantes "siempre" varía en las distintas actividades profesionales y poblaciones relevadas: tacto rectal, 94\%; necropsias, 77-89\%; cirugías, 61-73\%; partos, 49-68\%; podología bovina, $58 \%$; mientras que el uso de protectores oculares o faciales es escaso o nulo. En Veterinarios de grandes animales, el uso de guantes es más frecuente para los tactos rectales, la manipulación de abortos y las necropsias (Cuadro 1).

Cuadro 1. Frecuencia (\%) de Veterinarios rurales que usaron elementos de protección personal in labore (Tarabla et al., 2017).

\begin{tabular}{lllll}
\hline \multirow{2}{*}{ Elementos } & \multicolumn{2}{l}{ Actividad (n de encuestados que realizan la actividad) } & \multicolumn{3}{c}{ Frecuencia (\%) } \\
\cline { 2 - 4 } Guantes & Tacto rectal (543) & Siempre & A veces & Nunca \\
\cline { 2 - 5 } & Atención de partos (517) & 92,8 & 5,5 & 1,7 \\
\cline { 2 - 5 } & Cirugía (520) & 64,0 & 24,6 & 11,4 \\
\cline { 2 - 5 } & Necropsia (540) & 60,2 & 28,8 & 11,0 \\
\cline { 2 - 5 } & Manipulación de abortos (497) & 85,7 & 12,6 & 1,7 \\
\cline { 2 - 5 } & Vacunación antibrucélica (522) & 88,3 & 6,8 & 4,8 \\
\cline { 2 - 5 } & Podología bovina (403) & 33,5 & 19,2 & 47,3 \\
\hline Protector ocular / facial & Tacto rectal (511) & 27,3 & 27,5 & 45,2 \\
\cline { 2 - 5 } & Atención de partos (500) & 4,2 & 4,4 & 91,3 \\
\cline { 2 - 5 } & Cirugía (496) & 2,6 & 2,8 & 94,6 \\
\cline { 2 - 5 } & Necropsia (504) & 3,6 & 6,9 & 89,5 \\
\cline { 2 - 5 } & Manipulación de abortos (472) & 2,6 & 5,0 & 92,4 \\
\cline { 2 - 5 } & Vacunación antibrucélica (506) & 10,0 & 8,9 & 81,1 \\
\cline { 2 - 5 } & Podología bovina (450) & 2,7 & 4,3 & 93,0 \\
\hline Faja anatómica & Require esfuerzo físico (549) & 4,3 & 3,8 & 91,9 \\
\hline Protector auricular & Ruidosas (532) & 6,0 & 19,3 & 74,7 \\
\hline & & 0,4 & 3,0 & 96,6 \\
\hline
\end{tabular}

Si bien en algunos casos pueden ocurrir eventos imprevistos, como la rotura de los guantes al asistir bovinos durante el parto, no existen razones, fuera de la imprudencia, que puedan explicar las causas por las cuales no hayan utilizado los guantes durante la realización de cirugías, necropsias y vacunaciones antibrucélicas con Cepa 19 (Tarabla 2009, Tarabla et al. 2017). Similares observaciones se pueden hacer 
respecto a la falta de uso de protectores oculares o faciales; más aún, si se tiene en cuenta que la vía conjuntival es una de las formas más frecuentes de transmisión de la enfermedad más prevalente entre los veterinarios rurales, es decir, la brucelosis (Alvarez et al. 2007).

La frecuencia de uso de EPP "siempre" aparenta ser mayor entre los clínicos de pequeñas especies, tanto en el caso de los de guantes (cirugías $87 \%$, necropsias 83\%, partos $87 \%$ ); como de los barbijos o tapabocas (52, 39 y $26 \%$, respectivamente); los protectores oculares (39, 33 y $26 \%)$, respectivamente (Gómez de la Torre \& Tarabla 2015). Actualmente, se realizan estudios comparativos directos entre profesionales de grandes y pequeñas especies para corroborar o rechazar esta hipótesis.

La protección, entre quienes practican radiología en pequeños animales, es claramente insuficiente. Sólo el 23\% tenía licencia sanitaria habilitante; el 39\% estaba inscripto en el servicio de salud y ninguno usaba dosímetro para medir el grado de radiación que recibía, lo cual contradice lo estipulado legalmente. Aunque todos los profesionales usan delantal protector, sólo el 58\% utiliza siempre protector de tiroides y el $42 \%$ guantes (Gómez de la Torre \& Tarabla 2016). Los veterinarios suelen adquirir equipamientos usados, sin controles periódicos y con mantenimiento deficiente. Si a esto se agrega un uso incompleto de los EPP, el riesgo de padecer sobreexposición aumenta (Álvarez et al. 2007).

En el tránsito vehicular in itinere, la utilización del cinturón de seguridad "siempre" en rutas varía entre el 77 y el $80 \%$; mientras que en caminos rurales, sin pavimentar, baja al $46-47 \%$. La frecuencia de uso de la luz baja durante el día, por su parte, está en el $85-86 \%$ y el 52-54\%, respectivamente (Tarabla 2009, Signorini et al. 2014). La falta de constancia, en el uso de estos elementos de protección pasiva y activa del automotor, se une a la utilización de otros elementos que perturban una conducción correcta, como usar el teléfono celular (Figura 6).

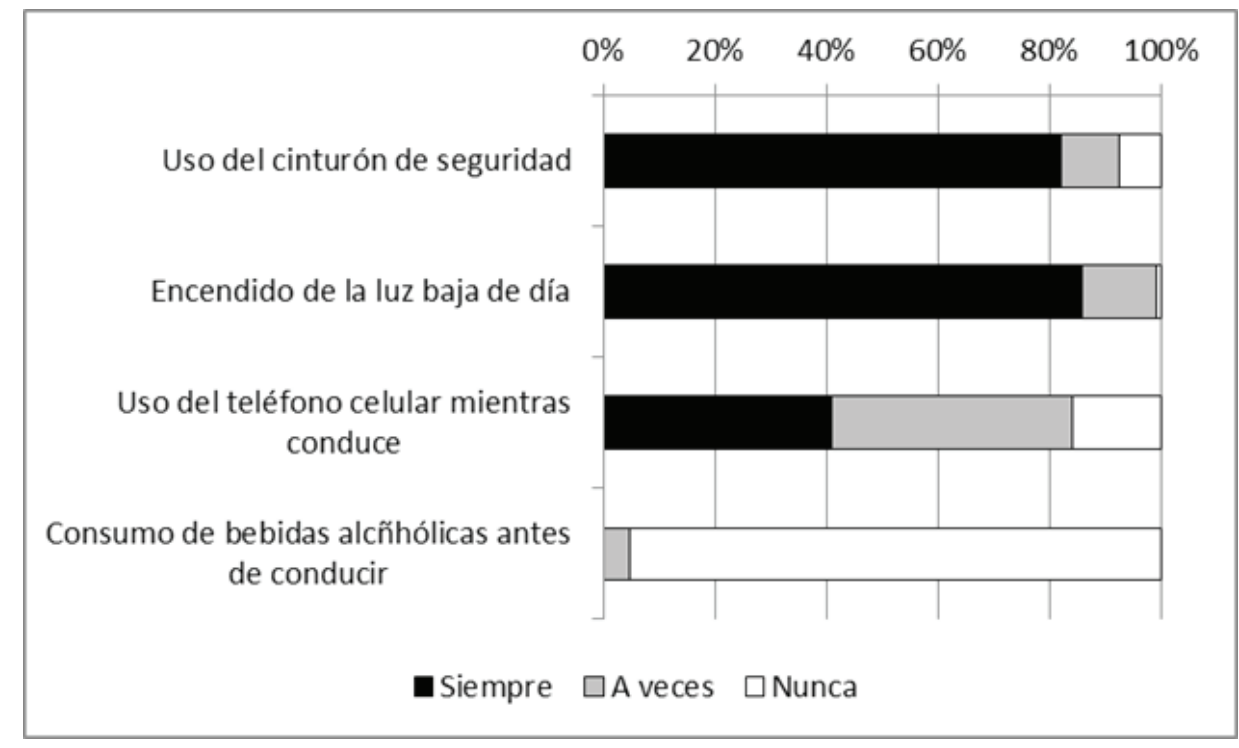

Figura 6. Factores asociados a la seguridad personal durante la conducción vehicular, in itinere, en Veterinarios de grandes animales $(\mathrm{n}=106)$ (Huertas et al. 2017a). 
Más del 50\% de los Veterinarios, de práctica mixta, consumían alimentos o hablaban por celular mientras conducían (Imoberdorf et al. $\left.2017^{c}\right)$. Esto es más frecuente entre los jóvenes $(\mathrm{P}=0,042)$ y los profesionales del sexo masculino $(\mathrm{P}=0,008)$ (Huertas et al. $2017^{\mathrm{a}}$, Imoberdorf et al. $2017^{\mathrm{c}}$ ). En trabajos realizados en otras regiones de Latinoamérica, el consumo de bebidas alcohólicas, es francamente superior a lo reflejado en la Figura 6. Aunque el 15\% de los encuestados consumía bebidas alcohólicas antes y durante el trabajo, sólo el 2\% lo considera un riesgo para la práctica profesional (López Cepeda et al. 2014). Tanto el cinturón de seguridad como la luz baja durante la conducción diurna las usan más frecuentemente las mujeres que los hombres $(\mathrm{P}<0$,01) (Tarabla 2009, Signorini et al. 2014). Es necesario destacar que el comportamiento del profesional en el tránsito in itinere, con su vehículo de trabajo, no necesariamente refleja su comportamiento durante el tránsito con su familia o en otras actividades.

Tanto la percepción de los riesgos ocupacionales como la frecuencia de uso de EPP, in labore e in itinere, están asociadas a variables socio-demográficas como: la región geográfica, la edad y el sexo de los profesionales. En general, la percepción y la utilización de EPP en tareas profesionales específicas es más frecuente entre las mujeres y los jóvenes $(\mathrm{P}<0,01)$ (Navarrete \& Tarabla 2014, Tarabla et al. 2017). Por el contrario, el uso de protección personal, ante la exposición al frío y el calor ambiental, es más frecuente en los profesionales de mayor edad $(\mathrm{P}<0,01)$ (Navarrete \& Tarabla 2016). No hay asociaciones entre percepciones y uso de EPP. Las correlaciones entre el uso de distintos elementos para una misma actividad son escasas o inexistentes, lo cual indica una real inconsistencia con el comportamiento profesional de autoprotección (Tarabla et al. 2017)..

\section{Disposición de elementos de protección personal y otros insumos.}

El 51\%, de 330 Veterinarios rurales, en Argentina, descartaba, en el campo, los guantes usados en necropsias, atención de partos o manipulación de abortos. Solamente el $4 \%$ los trataba como residuo patológico. El 4,5\% trataba las agujas descartables como residuo patológico o usaba botellas de plástico de refrescos como descartadores, el 12\% las incluía junto con la basura domiciliar y el 13\% las quemaba. El lavado, por separado, es una de las formas más frecuentes de disposición de la ropa de trabajo, mientras que su desinfección es una de las prácticas menos utilizadas (Meléndez et al. 2012). En un segundo relevamiento, efectuado en otra región del mismo país, uno de cada cuatro profesionales lavaba y desinfectaba el cuchillo de necropsia "a veces" o "nunca", y el 17,2\% lo utilizaba para otras tareas (Huertas et al. 2017 ) (Cuadro 2).

En clínicos de pequeños animales, uno de cada cuatro profesionales descartaba las agujas hipodérmicas en descargadores para residuos patológicos; mientras que, el resto las colocaba en recipientes no específicos (Gómez de la Torre \& Tarabla 2016). 
Rev. Ciencias Veterinarias, Vol. 35, N² 2, [65-84], ISSN: 2215-4507, julio-diciembre, 2017

Cuadro 2. Disposición de elementos de protección personal y otros insumos de trabajo en Veterinarios de grandes animales (Huertas et al. 2017 $)$.

\begin{tabular}{llccc}
\hline \multicolumn{1}{c}{ Elemento (n de encuestados) } & Acción & \multicolumn{3}{c}{ Frecuencia (\%) } \\
\cline { 3 - 4 } & & Siempre & A veces & Nunca \\
\hline Guantes de látex (105) & Descarte & 100 & 0,0 & 0,0 \\
Guantes de tacto (101) & & 99,0 & 1,0 & 0,0 \\
Protección respiratoria (20) & & 60,0 & 10,0 & 30,0 \\
Overol descartable (17) & & 29,4 & 35,3 & 35,3 \\
Agujas descartables (106) & & 80,2 & 18,9 & 0,9 \\
Jeringas descartables (106) & & 54,7 & 44,3 & 0,9 \\
Hojas de bisturí (102) & & 86,3 & 13,7 & 0,0 \\
\hline Cuchillo de necropsia (99) & Lavado & 90,9 & 6,1 & 3,0 \\
& Lavado y desinfección & 74,7 & 12,1 & 13,2 \\
& Uso para otras tareas & 7,1 & 10,1 & 82,8 \\
\hline Ropa de trabajo (106) & Lavado por separado & 70,8 & 11,3 & 17,9 \\
& Lavado y desinfección & 15,1 & 13,2 & 71,7 \\
& Lavado fuera del hogar & 9,4 & 1,9 & 88,7 \\
\hline Calzado de trabajo (106) & Lavado & 46,2 & 33,0 & 20,8 \\
\hline
\end{tabular}

\section{Prevención de riesgos laborales.}

Muchos Veterinarios encuentran inseguro su ambiente de trabajo y creen necesario recibir, regularmente, cursos de higiene y seguridad ocupacional. La labor, en algunas especialidades, como la radiología o el manejo de animales silvestres, puede requerir capacitaciones específicas (Álvarez et al. 2007, Lecaros et al. 2010). Sin embargo, sólo una minoría de los profesionales ha recibido capacitación sobre riesgos ocupacionales. La mayoría de ellos trabajaban en relación de dependencia, mientras que quienes ejercen la profesión libre de manera independiente estaban librados a su propio albedrío (Tarabla 2009, Imoberdorf et al. $2017^{c}$ ). La generación de conciencia, sobre los riesgos del ejercicio de la profesión, debe comenzar en la formación de grado. (Álvarez et al. 2002). A las carencias, en la capacitación continua de los Veterinarios de ejercicio profesional independiente, debe agregarse la falta de respaldo en caso de AL o EP. En un trabajo, realizado en clínicos de pequeñas especies, únicamente el 4,3\% poseía una cobertura específica para sus riesgos profesionales (Gómez de la Torre \& Tarabla 2014). Estos riesgos no se relacionan solamente con peligros biológicos, sino que incluyen otros orígenes que aumentan la probabilidad de accidentes in labore e in itinere. Un cambio de actitud, entre los profesionales, parece ser la condición primaria para lograr avances, pero sería de suma utilidad que los programas de educación continua incluyan los peligros a los cuales se ven enfrentados los profesionales. Por otra parte, los profesionales que trabajan en áreas académicas, pueden generar acciones para que los resultados obtenidos en las actividades de investigación vuelvan al territorio de origen de la información (Tarabla et al. 2017). 
El Veterinario debe conocer el comportamiento y los instintos de la especie animal con la cual trabaja, cuál es su zona ciega, cuál su punto de balance y cuál su zona de escape. Debe ser paciente y trabajar sin apuros. En grandes animales se debe evitar azuzar los animales con perros, gritos o golpes. El bienestar animal, el del profesional y sus colaboradores no son factores contrapuestos, por lo cual, las instalaciones deben estar diseñadas para comodidad del animal y del trabajador, para ser sometidas a un mantenimiento constante y evitar las improvisaciones derivadas de roturas. En grandes animales se debe trabajar a manga cerrada, sin elementos ajenos a las instalaciones como palos, alambres y sogas. En pequeñas especies, el uso de camillas regulables es recomendable para evitar lesiones lumbares. Los bozales y la sujeción de los pacientes por personal entrenado pueden prevenir mordeduras y rasguños. Generalmente, el dueño de la mascota no es un colaborador confiable.

El examen médico anual está lejos de ser una norma entre los Veterinarios (Tarabla 2009). Este debe incluir el diagnóstico de las zoonosis presentes en el área geográfica de práctica profesional. Los Veterinarios clínicos y los de laboratorios son considerados grupos de alto riesgo; deben estar vacunados preexposición en enfermedades como el tétanos o la rabia. Se debe guardar registro de las vacunaciones a las cuales se sometió. Después de diez años es difícil recordar cuándo fue la última vacunación antitetánica, por ejemplo. No se debe fumar, comer ni beber durante el trabajo. Cualquier gesto que lleve elementos a la boca o a los ojos durante el trabajo puede acarrear una zoonosis.

El manejo del material biológico debe ser de extremo cuidado. Cuando se trate de enfermedades zoonóticas o de fácil diseminación, los cadáveres no deben ser movidos del lugar si no se tiene certeza de que no contaminarán otros lugares o contagiarán a otros individuos. En áreas rurales, la recomendación de quemar o enterrar los cadáveres, es impracticable cuando se trata de animales de gran peso o masa corporal. Una opción es cubrir con cal y luego con un nylon, como el utilizado para la conservación de forrajes ensilados, asegurar los bordes para evitar que el clima u otros animales puedan removerlo. En la clínica de pequeñas especies, los residuos biológicos deben ser tratados como residuos patológicos y recogidos por empresas habilitadas en aquellas ciudades que cuenten con dicho servicio. Las muestras de material biológico, para su análisis en laboratorios de diagnóstico, deben enviarse sin demora, utilizando medios de trasporte seguros, Los frascos no deben tener pérdidas y deben estar rotulados claramente. En caso de remisión en bolsas plásticas, debe introducirse las mismas en una segunda bolsa para ser correctamente rotuladas.

Para prevenir heridas punzocortantes se deben evitar los apuros; tener una adecuada disponibilidad y calidad de personal para sujetar los pacientes. Esto es más fácil decirlo que hacerlo; porque, tanto en el consultorio como en el campo, muchas veces el profesional tiene que arreglárselas por sí mismo. Nunca se debe deambular con una aguja sin tapa o un cuchillo sin vaina. Las malas prácticas de manejo de agujas y cuchillos, por parte del profesional, son un mal ejemplo para el personal auxiliar, el cual debe ser entrenado apropiadamente. Se recomienda no volver a tapar las agujas utilizadas. Si es estrictamente necesario hacerlo, usar sólo una mano, forceps o re-tapador. En la clínica de pequeñas especies, las agujas no deben descartarse en contenedores temporarios o inapropiados, sino que se deben disponer, rápidamente, en contenedores específicos de fácil acceso. Estos no deben llenarse por encima del límite. Nunca se debe intentar sacar del contenedor agujas desechadas. En la práctica con grandes animales se puede utilizar una bolsa de residuos impermeable con lavandina y sus bordes asegurados en un tacho. 
Las jeringas automáticas, como las utilizadas en vacunaciones, no deben tener pérdidas; deben estar bien lubricadas. La carga de la vacuna, no se debe hacer a la altura de los ojos. El frasco puede introducirse en una bolsa plásticas, con cierre hermético, como las utilizadas en la conservación de alimentos congelados. Luego, se puede pinchar el frasco para que, de producirse "spray", quede en el interior de la bolsa. La vacunación se debe hacer con una mano, para no pellizcar con la mano opuesta y así evitar heridas punzantes al atravesar inadvertidamente ambos lados del pliegue.

Aunque sea obvio, que posesión y uso no son sinónimos, es bueno recordar que los EPP deben estar sobre el cuerpo del profesional o el estudiante, no apilados en un estante o guardados en un cajón. El uso de ropa específica: guantes, barbijos o tapabocas y protector ocular o facial (a los que se agregan las botas de goma en el trabajo a campo) debe ser parte de la rutina profesional. Inevitablemente, el uso EPP en: cirugías, tactos rectales, vacunaciones, necropsias, partos, manipulaciones de abortos, limpiezas de dientes en pequeñas especies, podología en bovinos y cualquier otra actividad profesional, va a depender de la decisión individual del profesional, estudiante o sus docentes. Esta decisión debe priorizar, siempre, la seguridad y no la comodidad o el precio. Otras protecciones adicionales, en casos puntuales, incluyen las fuentes de luz apropiadas y los protectores auriculares o respiratorios. En algunas regiones, el cuidado, ante las contingencias climáticas, es fundamental entre quienes trabajan al aire libre.

Las buenas prácticas viales, durante el tránsito in itinere, deben acatar simplemente las normas de seguridad vigentes en la legislación local. En muchas regiones, el tránsito vehicular en caminos rurales genera mucho polvo, el cual queda flotando en el ambiente; por ello, aunque no sea obligatorio, es aconsejable encender la luz baja durante el día.

El material descartable no debe ser reutilizado. Se debe eliminar de manera segura, ya sea desinfectándolo y quemándolo en el campo o retirándolo mediante una compañía autorizada para el transporte de residuos patológicos, en las ciudades con este servicio. El instrumental debe lavarse, desinfectar y esterilizar luego del uso. Otros elementos como: bozales, sogas y maneas para sujeción, luego de desinfectados deben guardarse en el sitio de trabajo, no en el hogar. La ropa de trabajo debe ser desinfectada y lavada por separado. Esto protegerá, tanto al profesional como a su familia.

Quien trabaje en diagnóstico por imágenes deberá cumplir con la legislación local vigente. Por ej: contar con licencia sanitaria habilitante o estar inscrito en el servicio de salud. Es crucial el empleo de dosímetro para conocer el grado de radiación al cual está expuesto; así como el uso de delantal, cuellera y guantes protectores. Quien sujeta al paciente debe estar igualmente protegido. La sala de radiología debe estar acorde con las normas de seguridad respectivas y el equipamiento debe someterse a controles periódicos que aseguren el mantenimiento indispensable.

\section{Conclusiones.}

La profesión veterinaria está íntimamente asociada con EP y AL. Los médicos veterinarios son los principales damnificados por la inobservancia de normas mínimas de prevención. Esta falencia se extiende hasta la misma enseñanza de grado. El escaso conocimiento de zoonosis, en ingresantes a la carrera, refuerza la necesidad de una temprana exposición de los estudiantes de veterinaria a temas relacionados con higiene y seguridad laboral. Los accidentes y enfermedades ocupacionales no deben 
asumirse como algo natural, de ocurrencia frecuente, que, como tales, no implican la necesidad de cambio alguno. Aunque, en el ejercicio de esta profesión, se deban asumir riesgos laborales, se necesita cambios de conducta negativas. Estos cambios implican saber qué, por qué y cómo hacer; también el querer hacer. Es necesario mejorar las condiciones de trabajo, concientizar las nuevas generaciones de profesionales y extender el conocimiento a la sociedad en general para disminuir la exposición a los diferentes peligros.

\section{Agradecimientos.}

Esta revisión fue producto de una invitación recibida para participar en las III Jornadas Nacionales y II Internacionales de Salud Pública Veterinaria desarrolladas en Heredia, Costa Rica del 4 al 6 de octubre de 2016.

El agradecimiento para la Escuela de Medicina Veterinaria de la Universidad Nacional de Costa Rica y especialmente para los colegas Leana Zumbado Gutiérrez y Juan José Romero Zúñiga.

\section{Referencias}

Álvarez, E., Larrieu, E. \& Cavagion, L. 1990. Aportes al conocimiento del riesgo del ejercicio de la profesión veterinaria. Vet. Arg. 7: 58-64. ISSN 1852-317X.

Álvarez, E., García Cachau, M., Campi, A. \& Larrieu, E. 2002. Normas de bioseguridad y seguridad laboral en Facultades de Ciencias Veterinarias de Argentina. Cien. Vet. 4: 35-40. ISSN: 1515-1883.

Álvarez, E. Peratta, D., García, M., Cavagión, L., Larrieu, E. \& Ferrán, A. 2007. Enfermedades y lesiones laborales en Médicos Veterinarios de Argentina. Cien Vet. 9: 49-67. ISSN 1515-1883.

Arce, C., León, D., Breña, M. \& Falcón, N. 2016. Accidentes y lesiones en estudiantes de Medicina Veterinaria y Zootecnia en una Universidad de Lima - Perú. Salud Tecnol. Vet. 4: 1-8. https://doi. org/10.20453/stv.v4i1.3081

Benzoni, A., Bertone, P., Ugnia, L. \& Tarabla, H. 2017 . Conocimientos, percepciones y comportamientos frente a riesgos biológicos en estudiantes de Medicina Veterinaria. $3^{\circ}$ Jorn. Enseñanza Cien. Vet., Asoc. Arg. Enseñanza Cien. Vet., Mar del Plata, Argentina, Libro de Resúmenes, p. 73. ISBN 978987-42-5470-2.

Benzoni, A., Bertone, P., Ugnia, L., Tarabla, H. 2017 . Higiene y seguridad en instalaciones de práctica de actividades hospitalarias en la carrera de Medicina Veterinaria. $3^{\circ}$ Jorn. Enseñanza Cien. Vet., Asoc. Arg. Enseñanza Cien. Vet., Mar del Plata, Argentina, Libro de Resúmenes, p. 74. ISBN 978987-42-5470-2.

Breña, J., Falcón, N., Fernández, C. \& Zuazo, J. 2014. Accidentes ocupacionales en personal que labora en clínicas y consultorios de animales de compañía, Lima 2010. Salud Tecnol. Vet. 2: 24-31. ISSN 2312-3907.

Carneiro, M., Giacomini, M. \& Costar, M. 2004. Leptospirosis asociada a la exposición ocupacional: estudio clínico y epidemiológico. Rev. Chil. Infect. 21: 339-344. http://dx.doi.org/10.4067/S071610182004000400008. 
Cristancho, D., Benítez, K. \& Góngora, A. 2012. Conocimientos sobre leptospirosis en estudiantes de veterinaria y seropositividad, Villavicencio, 2011. Orinoquia 16: 118-124. ISSN 0121-3709.

Dammert, N., Noé, N., Falcón, N., Lopera, L. \& Rodríguez, M. 2009. Exposición a Leptospira sp. en estudiantes de Medicina Veterinaria al inicio y término de la carrera. Rev. Inv. Vet. Perú 20: 114119. ISSN 1609-9117.

Gil, A., Piaggio, J., Di Pace, B., Rossi, J., Guedes, K, Rosas, D., Deluca, C., Serena, A. \& Barreto, A. 2010. Censo Nacional Veterinario del Uruguay, Univ. de la República - Min. Gan. Agric. \& Pesca - Soc. Med. Vet. del Uruguay, 98 pp. ISBN 978-9974-563-71-1.

Gómez de la Torre, N. \& Tarabla, H. 2015. Accidentes laborales, enfermedades profesionales y uso de elementos de protección personal en veterinarios de pequeños animales. InVet 17: 23-27. ISSN 1668-3498.

Góngora, A., Parra, J., Aponte, L. \& Gómez, L. 2008. Seroprevalencia de Leptospira spp. en grupos de población de Villavicencio, Colombia. Rev. Salud Pública 10: 269-278. ISSN 0124-0064.

Henzenn, H., Vitulich, C., Molineri, A., Signorini, M. \& Tarabla, H. 2017. Percepción de riesgos laborales en áreas rurales en estudiantes de escuelas agrotécnicas. $3^{\circ}$ Jorn. Enseñanza Cien. Vet., Asoc. Arg. Enseñanza Cien. Vet., Mar del Plata, Argentina. Libro de Resúmenes, p. 48. ISBN 978987-42-5470-2.

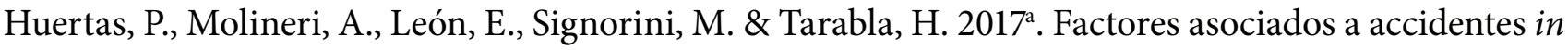
itinere en Veterinarios de grandes animales en la Provincia de Buenos Aires. $10^{\circ}$ Jorn. Internac. Vet. Práctica, Mar del Plata, Argentina. http://cvpba.org/wp-content/uploads/2017/09/1.EYSP_. POSTER2017.pdf

Huertas, P., León, E. \& Tarabla, H. 2017 . Zoonosis, uso y disposición de insumos de trabajo en Veterinarios de grandes animales. $10^{\circ}$ Jorn. Internac. Vet. Práctica, Mar del Plata, Argentina. http://cvpba.org/wp-content/uploads/2017/09/2.EYSP_POSTER2017.pdf

Imoberdorf, C., Signorini, M. \& Tarabla, H. 2017ª . Factores asociados a accidentes ocupacionales que dificultan o impiden el trabajo a veterinarios clínicos. XXXVI Jorn. Actualización Cien. Vet., Villa Giardino, Argentina. http://www.covetcba.com.ar/Capacitación

Imoberdorf, C., Signorini, M. \& Tarabla, H. 2017b. Factores asociados a zoonosis en Médicos Veterinarios de grandes y pequeños animales. XXXVI Jorn. Actualización Cien. Vet., Villa Giardino, Argentina. http://www.covetcba.com.ar/Capacitación

Imoberdorf, C., Signorini, M. \& Tarabla, H. 2017 . Adopción de prácticas seguras por veterinarios clínicos. XXXVI Jorn. Actualización Cien. Vet., Villa Giardino, Córdoba, Argentina. http://www. covetcba.com.ar/Capacitación

James, A., Siele, K., Harry, N., Suepaul, S., Stewart-Johnson, A. \& Adesiyun, A. 2013. Serological evidence of exposure to Leptospira spp. in veterinary students and other university students in Trinidad and Tobago. Interdisciplinary Perspectives Inf. Dis. Article ID 719049, 7 pp. http:// dx.doi.org/10.1d155/2013/719049 
Koziol, E., Vanasco, N.B., Signorini, M-L- \& Tarabla, H.D.. 2016. Conocimientos de zoonosis en operarios tamberos de la Provincia de Santa Fe, Argentina. InVet. 18: 45-52. ISSN 1514-6634.

Labarthe, N. \& Pereira, M.E.C. 2008. Biossegurança na experimentação e na clínica veterinária: pequenos animais. Ciênc. Vet. Tróp. Recife-PE, 11 supl. 1: 153-157. ISSN 1415-6326.

Langoni, H., Vasconcelos, C., Nitsche, M., Olbrich, S., Carvalho, L. \& Silvas, R. 2009. Fatores de risco para zoonoses em alunos do curso de medicina veterinária, residentes e pós-graduandos. Arq. Ciênc. Vet. Zool. UNIPAR, Umuarama 12: 115-121. ISSN 1415-8167.

Lecaros, A., Falcón, N., Elías, R. 2010. Accidentes ocupacionales y zoonosis en médicos veterinarios y cuidadores de zoológicos y zoocriaderos de la ciudad de Lima - Perú. Una Salud. Revista Sapuvet de Salud Pública 2: 27-42. ISSN 2027-8047.

López Cepeda, M., Andrade, R., Tarabla, H., Signorini, M. \& Molineri, A. 2014. Factores asociados con la presentación de accidentes laborales en veterinarios zootecnistas del departamento de Boyacá, Colombia. Salud Uninorte. 30: 23-33. http://dx.doi.org/10.14482/sun.30.1.4311.

Meléndez, C., Molineri, A., Tarabla, H. \& Signorini, M. 2012. Uso y disposición de elementos de protección personal y de materiales e instrumental cortopunzantes en la práctica Veterinaria. XIVo Congr. Soc. Biol., Casilda, Argentina, p. 231. ISSN 23141484.

Méndez, I., Trujillo, D., Camilo, C., Acero, E., L. \& Pachón, D. 2013. Seroprevalencia de Brucella spp en estudiantes de Medicina Veterinaria, Bogotá, Colombia. Rev. Univ. Ind. Santander. Salud 45: 39-48. ISSN 0121-0807.

Molineri, A., Signorini, M., Pérez, L. \& Tarabla, H. 2013. Zoonoses in rural veterinarians in the central area of Argentina. Aust. J. Rur. Hlth. 21: 285-290. DOI: 10.1111/ajr.12054

Molineri A., Signorini M., Ruiz, M., Marenghi M. \& Tarabla H. 2014 ${ }^{\text {a }}$ Awareness of zoonoses in freshmen entering the Veterinary School. Rev. Br. Ciên. Vet. 21:239-242. http://dx.doi.org/10.4322/ rbcv.2015.302

Molineri, A., Signorini, M. \& Tarabla, H. 2014 . Conocimiento de las vías de transmisión de las zoonosis y de las especies afectadas entre los trabajadores rurales. Rev. Arg. Microbiol. 46:7-13. DOI: 10.1016/S0325-7541(14)70041-0

Molineri, A., Signorini, M. \& Tarabla, H. 2015. Hazards for women and children in rural settings. Rev. Salud Pública. 17: 22-32. http://dx.doi.org/10.15446/rsap.v17n1.40090

Molineri, A., Signorini, M. \& Tarabla, H. 2016. Distribución espacial de accidentes, percepción de riesgos y uso de elementos de protección personal in itinere en veterinarios de grandes animales en la Provincia de Santa Fe. Analecta Vet. 36: 23-27. ISSN 1514-2590.

Navarrete, M. \& Tarabla, H. 2016. Factores asociados a los riesgos laborales y el uso de elementos de protección personal en la clínica de bovinos y equinos. XXV Congr. Panam. Vet., Panamá, CD. www.panvet.org/

Neira, P., Muñoz, N. \& Rosales, J. 2010. Infección por Cryptosporidium parvum en una mujer embarazada, inmunocompetente, con riesgo ocupacional. Rev. Chil. Infect. 27: 345-349. 
Nocifi, D., Carmaroni, J., Pereira de Jesus, L., Samara, S. \& Aldocírio de Araújo, J. 2003. Anticorpos contra o vírus rábico em seres humanos com atividades no Hospital Veterinário federal de Mato Grosso, Cuiabá, MT, Brasil. Rev. Soc. Br. Med. Trop. 36: 355-358. ISSN 1678-9849.

Olvera Yabur, A., Cú Chablé, L. \& Tarabla, H. 2016. Accidentes ocupacionales, zoonosis, percepción de riesgo y protección personal en estudiantes de Veterinaria de Campeche, México. XXV Congr. Panam. Vet., Panamá. www.panvet.org/

Olvera Yabur, A., López, C., Signorini, M. \& Tarabla, H. 2015. Frecuencia de accidentes en estudiantes de Medicina Veterinaria y Zootecnia de UA Baja California, México. Rev. Cien. Biol. Agropec. Tuxpán 2 (5). ISSN 2007-6940.

Quitián, H., Parra, J., Góngora, A., Parra, J., Gallego, J. \& Aponte, L. 2009. Seroprevalencia de infección por Leptospira spp. en auxiliares y veterinarios de consultorios de pequeños animales de Villavicencio (Colombia). Salud Uninorte 25: 47-55. ISSN 2011-7531.

Raso, T., Carrasco, A., Silva, J., Marvulo, M. \& Pinto, .A. 2009. Seroprevalence of antibodies to Chlamydophila psittaci in zoo workers in Brazil. Zoonoses Public Health. 57: 411-416. doi: 10.1111/j.1863-2378.2009.01237.x

Ribeiro de Araújo, F., Sarti, E., Crocci, A., Souza, V., Amorim, J., Queiróz, F., Pires de Araújo, C., Espinola, C. 2000. Anticorpos contra Toxoplasma gondii em estudantes de Medicina Veterinaria de Campo Grande, MS, Brasil. Cienc. Rural Santa Maria 30: 1017-1019. http://dx.doi.org/10.1590/ S0103-84782000000600016

Riemann, H., Brant P., Franti C., Stormont C. 1974. Antibodies to Toxoplasma gondii and Coxiella burnetti among students and other personnel in veterinary colleges in California and Brazil. Am. J. Epidemiol. 100: 197-208. ISSN 0002-9262.

Signorini, M., Pérez L., Tarabla, H. \& Molineri, A. 2014. Accidentes laborales en veterinarios rurales. Avances Cien. Vet., 29: 36-41. ISSN 0719-5273.

Suárez, M., Llorens, F., Cepero, O., Retureta, M. \& González-Marti, T. 2005. Conocimientos que tienen Médicos Veterinarios no vinculados a la salud pública en la provincia Ciego de Ávila, Cuba sobre algunas zoonosis. Rev. Bioméd. 16: 221-226. ISSN 0120-4157.

Suescún Carrero, S., Heredia, D., Mulato, Y., Pulido, M. 2017. Seroprevalencia de infección por Leptospira y factores de riesgo en estudiantes de una universidad de Colombia. Nova 15: 131-138. ISSN 1794-2470.

Tarabla, H. 2009. Riesgos de trabajo en veterinarios del centro-oeste de la Provincia de Santa Fe, Argentina. InVet, 11: 39-47. ISSN 1514-6634.

Tarabla, H. \& Fernández, G. 2009. Conocimiento sobre zoonosis en el ámbito urbano de la ciudad de Coronda, Santa Fe. Rev. FAVE Cien. Vet. 8: 11-14. ISSN 1666-938X.

Tarabla, H., Molineri, A., Robin, H. \& Signorini, M. 2016. Riesgos ocupacionales en estudiantes de veterinaria. XXV Congr. Panam. Vet., Panamá, CD. www.panvet.org/

Tarabla, H., Hernández, A., Molineri, A. \& Signorini, M. 2017. Percepción y prevención de riesgos 
ocupacionales en veterinarios rurales. Rev. Vet. Univ. Nac. Nordeste. Aceptado ISSN 1669-6840.

Tarabla, H., Signorini, M., Molineri, A., Vitulich, C., Henzenn, H., Erbetta, H. 2017. Manejo seguro de animales. Intentando cerrar la brecha entre investigación y extensión. $3^{\circ}$ Jorn. Enseñanza Cien. Vet. Asoc. Arg. Enseñanza Cien. Vet., Mar del Plata, Argentina, Libro de Resúmenes, p. 70. ISBN 978-987-42-5470-2.

Torres da Silva, D., Caldas Menezes, R., Vasconcellos Carvalhaes de Oliveira, R. Valente Pacheco, T. \& Pereira, S. 2011. Percepções de estudantes de Medicina Veterinária do Rio de Janeiro relacionadas à biossegurança e esporotricose. Com. Ciências Saúde. 22: 327-334. ISSN 1980-0584.

Trabattoni, E., Lavaroni, O., Vera, E. \& García, N. 2004. Prevalencia de Brucella abortus, canis y ovis en alumnos y docentes de Ciencias Veterinarias en Esperanza en el año 2002. Rev. FAVE 3: 25-31. ISSN 1666-938X.

Trabattoni, E., Lavaroni, O., Vera, E., García, N., Dalla Fontana, M., Achkar, G. \& Rossi, A. 2008. Prevalencia de anticuerpos anti Toxoplasma gondii y Trypanosoma cruzi en alumnos de Ciencias Veterinarias de la Universidad Nacional del Litoral, Esperanza, 2006. Rev. FAVE 7: 83-90. ISSN 1666-938X.

Ugnia L., Trolliet J. \& Tarabla H. 2017. Accidentes laborales en Veterinarios deducados a la producción porcina. Rev. Salud Pública Univ. Nac. Córdoba, Ed. Especial p. 33. ISSN 1852-9429.

Vallejo, D., Benavides, C., Astaiza, J., Higidio, P. \& Benavides M. 2016. Determinación de las medidas de bioseguridad en clínicas y consultorios de pequeños animales en la ciudad de Pasto, Nariño. Rev. Biosalud 15: 55-65. DOI: 10.17151/biosa.2016.15.2.6

Villar, G. \& Ortiz, R. 2016. Accidentes ocupacionales en trabajadores relacionados con animales silvestres en el Parque Zoológico Nacional de Cuba. Rev. Cubana Salud y Trabajo 17: 15-20. ISSN 1991-9395. 